\title{
Fukuchi, Takao and Marco Antonio F.H. Cavalcanti (Eds.) : Modeling the Brazilian Economy: Macroeconomics, Social Security and Con- sumer Behavior, Rio de Janeiro, IPEA, 2003. 264p.
}

\author{
Kobe University Nobuaki Hamaguchi
}

This book came out from the joint study project (1999-2002) between Japan International Cooperation Agency (JICA) and Instituto de Pesquisa Econômica Aplicada (IPEA), a Brazilian government research institute for applied economic research, which aimed at strengthening IPEA's technical capability in economic policy modeling. The Japanese side was headed by Professor Takao Fukuchi. This volume clearly shows potential usefulness of intellectual aid to developing countries.

It is composed in an interesting form, consisting of sets of dialogues between Brazilian and Japanese researchers and some joint papers. Following the brief Introduction (Fukuchi and Cavalcanti), Chapter 2 (Levy and Barbosa) gives a comprehensive overview of the historical process of the Brazilian economy between 1970s and early 2000s. This period is remembered by high inflation and intense instability. This chapter explains the nature of macroeconomic imbalances and problems of anti-inflation measures that were implemented during 1980s and 90s without success. Price stability was finally achieved by the Real Plan which was introduced in 1994, but the authors point out that restoring sustained economic growth and addressing poverty remain as major tasks.

Chapter 3 consists of two papers. Chapter $3 \mathrm{~A}$ (Cavalcanti) describes the development of the annual macroeconomic model (MOPSE-B) for projections and policy simulation developed by IPEA since mid-1980s. It also gives accounts to new salient features of the model: endogenous determination of exchange rate and equations for the labor market. The former has become necessary because of the transition from fixed to floating exchange rate regime of the Brazilian economy after the policy reform in 1999. The issue of the labor market is particularly serious concern for the Brazilian policy makers due to the problems of low growth and poverty as discussed in Chapter 1. Chapter 3B (Obayashi) provides the final test of the MPOSE-B based on the simplified version of the model to check the sample tracking performance. It shows that the model represents well the real sector of the economy, while it does not perform well on other sectors.

The same kind of exercise was carried out for IPEA's quarterly macroeconomic model in Chapter 4. Chapter 4A (Cavalcanti) explains the basic characteristics of the model. Major constraint by the time of the study project was the lack of the quarterly national account data, which forced IPEA to estimate the demand side using the time-series technique. This problem must have overcome today because the Brazilian statistical bureau (IBGE) has published the quarterly GDP data since 2002. Chapter 4B (Tokunaga) constructs a quarterly macroeconomic model. The final test shows that this model represents remarkably well the Brazilian economy between the fourthquarter in 1994 and the second-quarter in 2002. 
Chapter 5 (Fukuchi) proposes to construct a monthly macroeconomic model in order to clarify the economic structure, especially to understand the interaction among monetary, real, and policy aspects. The author first presents the version 1 model which treats as exogenously given such variables as the short-term interest rate, M1, M2, and the net public-sector borrowing requirement ; and the version 2 model that endogenized these variables through introduction of reaction functions on such policy variables for the fiscal and monetary authority. He found that the final test of the version 2 model did not give satisfactory results for the policy variables, yet the model fits nicely to the private sector. The chapter concludes that the construction of the monthly model for the Brazilian economy is actually feasible. This conclusion is remarkable in view of high instability of the Brazilian macroeconomy at the time when this study was conducted.

Chapter 6 (Obayashi) gives insightful comments on usefulness of stochastic simulation and multiplier analysis to understand the dynamic properties of annual, quarterly, and monthly models developed in this study when they are used for the purpose of forecasting. The author also suggests that these techniques will help to identify possible source of fluctuations and lack of robustness of the results of the model. Chapter 7 summarizes main conclusions of the foregone part.

Chapters 8 and 9, although they are not directly related to the main theme of the book, present interesting empirical evaluation of the public social security system in Brazil.

Finally, Chapter 10 (Asano and Fiuza) studies consumer behavior through a microeconometic analysis. This provides robust estimates of price and expenditure elasticities of seven categories of consumption of goods and services. The study found negativity of the Hicks substitution matrix from the micro-econometric analysis of the consumption behavior, as predicted in microeconomic theory.

After the conclusion of the JICA-IPEA project, Brazil starts to enjoy sustained economic growth with price stability. Disappointingly, in this new economic scenario, IPEA under the current administration since 2007 has abandoned the short-term macroeconomic projections, arguing that a public institution should focus on long-term issues. The local media, however, suspected that political interests were involved in this decision, since IPEA tended to forecast more pessimistic scenario. This caused outflow of researchers from IPEA and caused certain detriment in IPEA's capability and the reputation as an independent academic institution. 